\title{
Training with supplemental oxygen in patients with COPD and hypoxaemia at peak exercise
}

\author{
J.M. Rooyackers, P.N.R. Dekhuijzen, C.L.A. Van Herwaarden, H.T.M. Folgering
}

Training with supplemental oxygen in patients with COPD and hypoxaemia at peak exercise. J.M. Rooyackers, P.N.R. Dekhuijzen, C.L.A. Van Herwaarden, H.T.M. Folgering. (c)ERS Journals Ltd 1997.

ABSTRACT: Supplemental oxygen has acute beneficial effects on exercise performance in patients with chronic obstructive pulmonary disease (COPD). The purpose of this study was to investigate whether oxygen-supplemented training enhances the effects of training while breathing room air in patients with severe COPD.

A randomized controlled trial was performed in 24 patients with severe COPD who developed hypoxaemia during incremental cycle exercise (arterial oxygen saturation $\left(\mathrm{Sa}_{\mathrm{a}} \mathrm{O}_{2}\right)<90 \%$ at peak exercise). All patients participated in an in-patient pulmonary rehabilitation programme of 10 weeks duration. They were assigned either to general exercise training while breathing room air (GET/RA group: forced expiratory volume in one second (FEV1) $38 \%$ of predicted; arterial oxygen tension $\left(\mathrm{Pa}_{\mathrm{a}} \mathrm{O}_{2}\right) 10.5 \mathrm{kPa}$ at rest; $\mathrm{Pa}, \mathrm{O}_{2} 7.3 \mathrm{kPa}$ at peak exercise), or to GET while breathing supplemental oxygen (GET/O $\mathrm{O}_{2}$ group: FEV1 $29 \%$ pred; $P_{a}, O_{2} 10.2 \mathrm{kPa}$ at rest; $P_{\mathrm{a}, \mathrm{O}_{2}} 7.2 \mathrm{kPa}$ at peak exercise). $\mathrm{Sa}_{\mathrm{a}, \mathrm{O}_{2}}$ was not allowed to fall below $90 \%$ during the training. The effects on exercise performance while breathing air and oxygen, and on quality of life were compared.

Maximum workload $\left(W_{\max }\right)$ significantly increased in the GET/RA group (mean (sD) 17 (15) W, p<0.01), but not in the GET/ $\mathrm{O}_{2}$ group (7 (25) W). Six minute walking distance (6MWD), stair-climbing, weight-lifting exercise (all while breathing room air) and quality of life significantly increased in both groups. Acute administration of oxygen improved exercise performance before and after training. Training significantly increased $W$ max, peak carbon dioxide production $\left(V^{\prime} \mathrm{CO}_{2}\right)$ and 6MWD while breathing oxygen in both groups. Differences between groups were not significant.

Pulmonary rehabilitation improved exercise performance and quality of life in both groups. Supplementation of oxygen during the training did not add to the effects of training on room air.

Eur Respir J 1997; 10: 1278-1284.
Dept of Pulmonary Diseases, University of Nijmegen, Medical Centre Dekkerswald, The Netherlands.

Corresponding author: J.M. Rooyackers Dept of Pulmonary Diseases

University of Nijmegen

Medical Centre Dekkerswald

P.O. Box 9001

6560 GB Groesbeek

The Netherlands

Keywords: Chronic obstructive pulmonary disease

exercise

hypoxaemia

oxygen

pulmonary rehabilitation

training

Received: October 241996

Accepted after revision February 201997

This study was supported by a grant from the Netherlands Asthma Foundation (90.22).
Hypoxaemia may occur during exercise in patients with chronic obstructive pulmonary disease (COPD). This is caused by alveolar hypoventilation, diffusion limitation, shunt, ventilation-perfusion inhomogeneity and a low mixed venous oxygen tension $\left(P_{\bar{v}}, \mathrm{O}_{2}\right)$ (low cardiac output) [1]. Exercise-induced hypoxaemia will raise the pulmonary artery pressure during exertion, and may contribute to the decreased exercise tolerance in these patients [2].

Acute administration of oxygen has been shown to improve exercise performance in patients with COPD [3-6]. These acute effects of oxygen have been observed both in normoxic patients and in patients who are hypoxaemic at rest or during exercise. Several mechanisms may be involved, including reduction in ventilatory response to exercise (reduced ventilatory equivalent for carbon dioxide $\left.\left(V^{\prime} \mathrm{E} / V^{\prime} \mathrm{CO}_{2}\right)\right)$ [6], ventilatory muscle recruitment [7] and delayed ventilatory muscle fatigue [8, 9], improved aerobic capacity of the working muscles [10] and a reduction in breathlessness [11].
As a consequence, patients with COPD would be expected to benefit from supplemental oxygen during the training. Indeed, recent guidelines recommend the administration of oxygen during exercise training in patients with exercise-induced hypoxaemia [12]. Whether this approach results in a further improvement in exercise performance as compared to training on room air has not been fully clarified. Many studies have investigated the effects of training in patients with COPD. Some of these studies included a small number of patients who developed hypoxaemia during exercise and received supplemental oxygen during the training, whereas patients who did not desaturate trained on room air [13-15]. Other, uncontrolled, studies have shown that oxygen-supplemented exercise training increased exercise performance [16-17]. However, in these studies no comparison was made with a control training group breathing room air.

We hypothesized that the administration of oxygen enables patients with COPD who develop hypoxaemia during exercise to achieve higher exercise intensities 
during the training. If so, this treatment might induce an additional physiological training effect on the cardiocirculatory system and the peripheral muscles in terms of increased oxygen delivery, peripheral oxygen extraction and muscle oxygen utilization. As a result, training with oxygen might also enhance exercise performance on room air. To test this hypothesis, we performed a controlled study to compare the effects of training with and without supplemental oxygen on exercise performance and quality of life in patients with severe COPD and hypoxaemia at peak exercise due to a diffusion-perfusion limitation.

\section{Methods}

\section{Study design and patients}

Twenty four patients with stable COPD [18] entered the study; all were referred to our hospital for pulmonary rehabilitation. They met the following inclusion criteria: hypoxaemia (arterial oxygen saturation $\left(\mathrm{Sa}, \mathrm{O}_{2}\right)$ $<90 \%$ ) at maximum exercise, and an increase in alveolar-arterial difference in oxygen tension $\left(P(\mathrm{~A}-\mathrm{a}) \mathrm{O}_{2}\right)$ of at least $2 \mathrm{kPa}$ from rest to maximum exercise during maximal incremental cycle exercise. Patients were excluded if they had a resting $P \mathrm{a}, \mathrm{O}_{2}$ of less than $8.5 \mathrm{kPa}$, a mean nocturnal $\mathrm{Sa}_{2} \mathrm{O}_{2}$ of less than $90 \%$, a mean pulmonary artery pressure $\left(\bar{P}_{\text {pa }}\right)$ of more than $25 \mathrm{mmHg}$ measured at rest by Doppler echocardiography [19], and if they had neuromuscular or cardiovascular disease.

All patients were ex-smokers. Their medication was not changed during the study. They were familiar with the procedures of exercise testing. The patients were randomly allocated either to general exercise training while breathing room air (GET/RA), or GET while breathing supplemental oxygen $\left(\mathrm{GET} / \mathrm{O}_{2}\right)$ at a flow rate of 4 $\mathrm{L} \cdot \mathrm{min}^{-1}$ through a dual-prong nasal cannula. Informed consent was obtained from each patient. The study was approved by the Hospital Ethics Committee.

\section{Pulmonary rehabilitation programme}

All patients participated in a multidisciplinary inpatient programme for 10 weeks, which consisted of physical training, breathing retraining, physical therapy (relaxation and mobilization exercises), education and psychosocial support.

General exercise training (GET). Training consisted of dynamic and isometric strength training and specific training of daily life activities. Training sessions were held 5 days per week and had a mean duration of 80 min, including periods of rest [20]. GET comprised the following exercises: interval cycling ( $2 \mathrm{~min}$ of exercise alternated with $2 \mathrm{~min}$ of rest for $20 \mathrm{~min}$ ); rowing (5 min); dynamic exercises for the muscles of the arm and shoulder girdle using a pulley ( $5 \mathrm{~min})$, and for the muscles of the back and abdomen by lifting the upper body and the legs, respectively, from the supine position (5 min); isometric strength training of the arms, shoulder girdles and legs (3 min); stair-climbing (3 min); sitting down and getting up from a chair alternating with slalom walking ( $5 \mathrm{~min}$ ); and arm exercise by moving a weight of $1-2 \mathrm{~kg}$ between racks at $20 \mathrm{~cm}$ above and below shoulder level (5 $\mathrm{min})$.
All sessions were supervised by a physiotherapist. $\mathrm{Sa}, \mathrm{O}_{2}$ during exercise was monitored with a pulse oximeter using a finger probe (Oxyshuttle, Sensor Medics, Bilthoven, The Netherlands). Exercise training was started at low workloads. After the first week, the exercise intensity was gradually increased as tolerated by the patients [21]. In both groups, the work rate was not allowed to exceed the level at which $\mathrm{Sa}_{\mathrm{a}} \mathrm{O}_{2}$ fell below $90 \%$.

\section{Outcome measures}

Pulmonary function tests. Spirometry and transfer coefficient for carbon monoxide (KCO, single-breath) were performed according to European Respiratory Society (ERS) standards [22]. All tests, including measurement of $\bar{P}$ pa at rest, were repeated at the end of the training period.

Maximal incremental cycle exercise test. The patients cycled on an electrically-braked cycle ergometer (Lode, Groningen, The Netherlands) at a pedalling rate of 60 revolutions per minute (rpm), breathing room air. The work rate was increased each minute by $10 \%$ of the estimated maximal workload $(W \max )$ until exhaustion [23]. Arterial blood samples were drawn from an indwelling catheter in the brachial artery. Minute ventilation $\left(V^{\prime} \mathrm{E}\right)$, oxygen consumption $\left(V^{\prime} \mathrm{O}_{2}\right)$ and carbon dioxide production $\left(V^{\prime} \mathrm{CO}_{2}\right)$ were measured every $30 \mathrm{~s}$ by a mixing chamber ergospirometry unit (Oxycon IV, Mijnhardt, Maarsen, The Netherlands). Breathlessness was scored every $3 \mathrm{~min}$, and at the end of exercise, on a modified Borg scale [24]. $V^{\prime}$ Emax was related to predicted maximum exercise values $\left(V^{\prime}\right.$ Emax predicted $=37.5 \times$ forced expiratory volume in one second (FEV1)) [25].

Single-stage cycle exercise test. After $1 \mathrm{~min}$ of unloaded pedalling, exercise was performed at a constant workload of $65 \%$ of the actual $W \max$. Endurance cycling time was measured. The test was terminated when the patient could not sustain exercise any longer, or after a maximum of $15 \mathrm{~min}$. The same measurements were made as during the maximal incremental test, except for blood gas analysis.

Activities of daily life. After 3 practice tests, the $6 \mathrm{~min}$ walking distance (6MWD) was measured in a gymnasium, while standardized encouragement was given [26, 27]. $\mathrm{Sa}, \mathrm{O}_{2}$ was measured continuously and breathlessness was scored at the end of the test.

Stair-climbing was performed on an exercise staircase with a hand-rail, which had four steps for going up, a plateau, and three steps for going down. The number of rounds during $5 \mathrm{~min}$ of exercise were counted.

During weight-lifting the patients held a weight of 2 $\mathrm{kg}$ in the dominant hand and moved it between racks at $20 \mathrm{~cm}$ above and below shoulder level. The number of lifts to both levels during $3 \mathrm{~min}$ was counted [28].

Acute effects of supplemental oxygen on exercise performance. The maximal incremental cycle exercise test, the single-stage exercise test and the 6MWD were repeated while oxygen was supplied at a flow rate of 4 $\mathrm{L} \cdot \mathrm{min}^{-1}$. Resting periods between tests lasted at least 4 
h. During oxygen breathing, it was not possible to measure $V^{\prime} \mathrm{O}_{2}$, and blood gas analysis was not performed.

Quality of life. Quality of life was assessed by means of the Chronic Respiratory Disease Questionnaire (CRDQ) [29]. The questionnaire examines the dimensions: dyspnoea, fatigue, emotional function and mastery. Altogether, 20 items are scored on a 7-point scale (maximum score 140 points; a higher score indicates a better quality of life). The test was administered at the start of the study and 6 weeks after completion of the pulmonary rehabilitation programme.

Statistical analysis. The data were analysed with the Statistical Analysis System (SAS) package (SAS Institute Inc., Cary, NC, USA). The results were expressed as mean $\pm \mathrm{SD}$. Changes within the training groups were compared with the Wilcoxon test for paired samples. Differences between the groups were compared with the Kruskal Wallis test (Chi-squared approximation). The correlation between various parameters was tested with the Spearman correlation coefficient. Since multiple comparisons were performed, the level of significance was set at a p-value less than 0.01 .

\section{Results}

\section{Pulmonary function tests}

The patients had severe airway obstruction and emphysema, as suggested by hyperinflation. They had a reduced $K C O$ and an elevated resting $P(\mathrm{~A}-\mathrm{a}) \mathrm{O}_{2}$, but they were normoxic at rest. Anthropometrics and resting pulmonary function remained unchanged after pulmonary rehabilitation. No significant differences were present between groups (table 1).

Table 1. - Anthropometrics and resting pulmonary function before and after pulmonary rehabilitation

\begin{tabular}{|c|c|c|c|c|}
\hline & \multicolumn{2}{|c|}{ GET/RA } & \multicolumn{2}{|c|}{$\mathrm{GET} / \mathrm{O}_{2}$} \\
\hline & Before & After & Before & After \\
\hline Patients $\mathrm{n}$ & \multicolumn{2}{|c|}{12} & \multicolumn{2}{|c|}{12} \\
\hline Sex $M / F$ & \multicolumn{2}{|c|}{$10 / 12$} & \multicolumn{2}{|c|}{$\begin{array}{r}10 / 12 \\
63+5\end{array}$} \\
\hline Age yrs & \multicolumn{2}{|c|}{$59 \pm 13$} & \multicolumn{2}{|c|}{$63 \pm 5$} \\
\hline $\mathrm{BMI} \mathrm{kg} \cdot \mathrm{m}^{-2}$ & $23.2 \pm 1.6$ & $23.0 \pm 1.6$ & $22.5 \pm 2.2$ & $22.1 \pm 2.0$ \\
\hline TLC $\%$ pred & $114 \pm 20$ & $110 \pm 11$ & $109 \pm 17$ & $110 \pm 22$ \\
\hline IVC $\%$ pred & $93 \pm 19$ & $95 \pm 17$ & $87 \pm 16$ & $98 \pm 23$ \\
\hline \multirow{2}{*}{$\begin{array}{l}\text { FEV } 1 ~ \\
\end{array}$} & $1.2 \pm 0.5$ & $1.2 \pm 0.5$ & $0.9 \pm 0.3$ & $1.0 \pm 0.4$ \\
\hline & $38 \pm 11$ & $38 \pm$ & $29 \pm 7$ & $33 \pm 9$ \\
\hline$K \mathrm{CO} \%$ pred & $37 \pm 14$ & $40 \pm 15$ & $30 \pm 14$ & $30 \pm 15$ \\
\hline $\bar{P}$ pa $\mathrm{mmHg}$ & $13 \pm 3$ & $16 \pm 7$ & $17 \pm 7$ & $15 \pm 5$ \\
\hline$P \mathrm{a}, \mathrm{O}_{2} \mathrm{kPa}$ & $10.5 \pm 1.1$ & $10.2 \pm 1.3$ & $10.2 \pm 1.6$ & $9.5 \pm 2.0$ \\
\hline $\mathrm{Pa}_{1} \mathrm{CO}_{2} \quad \mathrm{kPa}$ & $5.0 \pm 0.8$ & $4.9 \pm 0.6$ & $5.1 \pm 1.1$ & $5.3 \pm 1.1$ \\
\hline$P(\mathrm{~A}-\mathrm{a}), \mathrm{O}_{2} \quad \mathrm{kPa}$ & $4.4 \pm 0.9$ & $5.2 \pm 1.6$ & $4.6 \pm 1.9$ & $5.5 \pm 1.3$ \\
\hline
\end{tabular}

Values are presented as mean \pm SD. GET/RA: general exercise training/room air; GET/O $/ \mathrm{O}_{2}$ : general exercise training/supplemental oxygen; M: male; F: female; BMI: body mass index; TLC: total lung capacity (He-dilution); IVC: inspiratory vital capacity; KCO: transfer coefficient for carbon monoxide (single-breath); $\bar{P}$ pa: mean pulmonary artery pressure; $P \mathrm{a}_{2} \mathrm{O}_{2}$ : arterial oxygen tension; $P \mathrm{a}, \mathrm{CO}_{2}$ : arterial carbon dioxide tension; $P(\mathrm{~A}-\mathrm{a}), \mathrm{O}_{2}$ : alveolar-arterial difference in oxygen tension; $\%$ pred: percentage of predicted value. No significant differences were present between groups.

\section{Cycle exercise intensity during the training}

During the last 6 weeks of pulmonary rehabilitation, the mean (SD) workload achieved during interval cycle exercise training in the GET/RA and the $\mathrm{GET} / \mathrm{O}_{2}$, group was 114 (32) and 124 (43)\%, respectively, of $W \max$ during maximal incremental cycle exercise at the start of the study (GET/RA versus $\left.\mathrm{GET} / \mathrm{O}_{2} ; \mathrm{p}=0.12\right)$.

\section{Exercise testing on room air}

During maximal incremental cycle exercise before training, $V^{\prime} \mathrm{E}$ approached or exceeded predicted maximal values. $P \mathrm{a}, \mathrm{CO}_{2}$ increased by less than $1 \mathrm{kPa}$, while $P \mathrm{a}, \mathrm{O}_{2}$ decreased and $P(A-a) \mathrm{O}_{2}$ increased by approximately 3 $\mathrm{kPa}$ in both groups (table 2). Training increased $W \max$ by $17(15) \mathrm{W}(\mathrm{p}<0.01)$ in the GET/RA group, and by 7 (25) W (p=0.1) in the GET/O $\mathrm{O}_{2}$, group. Peak $V^{\prime} \mathrm{E}, V^{\prime} \mathrm{O}_{2}$, $V^{\prime} \mathrm{CO}_{2}$ and the change in base excess ( $\Delta$ base excess) were similar after training in both groups. $\mathrm{Pa}, \mathrm{O}_{2}$ at $\mathrm{Wmax}$ showed a further decrease after training in both groups, which was significant in the $\mathrm{GET} / \mathrm{O}_{2}$ group. Exercise efficiency $\left(\mathrm{W} / \mathrm{V}^{\prime} \mathrm{O}_{2}\right)$ at peak exercise on room air increased by $13(23) \mathrm{W} /\left(\mathrm{L} \cdot \mathrm{min}^{-1}\right)$ in the GET/RA group $(\mathrm{p}<0.01)$, and by $10(25) \mathrm{W} /\left(\mathrm{L} \cdot \mathrm{min}^{-1}\right)$ in the $\mathrm{GET} / \mathrm{O}_{2}$ group $(\mathrm{p}=0.1)$. In both groups, the reduction in dyspnoea score was about 1.3 points $(\mathrm{p}=\mathrm{NS})$.

The variability between patients in cycling time during single-stage exercise was large. At the start of the study, only three patients were able to cycle at least 10 min, whereas 14 patients stopped within 5 min of exercise. Training did not improve cycling time in the GET/ $\mathrm{RA}$ group. In the $\mathrm{GET} / \mathrm{O}_{2}$ group, the increase in cycling time $(2.2(4.2) \mathrm{min})$ was not significant $(\mathrm{p}=0.1)$ (table $3)$.

The 6MWD increased significantly by 123 (77) $\mathrm{m}$ in the GET/RA group and by $86(77) \mathrm{m}$ in the $\mathrm{GET} / \mathrm{O}_{2}$ group. This was achieved at a higher cardiac frequency $(f \mathrm{C})$ in both groups, which was significant only in the $\mathrm{GET} / \mathrm{O}_{2}$, group (table 3).

Table 2. - Maximal incremental cycle exercise test breathing room air before and after pulmonary rehabilitation

\begin{tabular}{|c|c|c|c|c|}
\hline & \multicolumn{2}{|c|}{ GET/RA } & \multicolumn{2}{|c|}{$\mathrm{GET} / \mathrm{O}_{2}$} \\
\hline & Before & After & Before & After \\
\hline$W_{\max } \mathrm{W}$ & $70 \pm 51$ & $87 \pm 58 * *$ & $58 \pm 33$ & $65 \pm 39$ \\
\hline$f_{\mathrm{C}}$ beats. $\mathrm{min}^{-1}$ & $133 \pm 21$ & $132 \pm 23$ & $126 \pm 17$ & $126 \pm 19$ \\
\hline$V^{\prime} \mathrm{E} \quad \mathrm{L} \cdot \mathrm{min}^{-1}$ & $43 \pm 21$ & $43 \pm 21$ & $35 \pm 15$ & $37 \pm 17$ \\
\hline$\%$ pred & $96 \pm 23$ & $95 \pm 18$ & $101 \pm 23$ & $92 \pm 13$ \\
\hline$V^{\prime} \mathrm{O}_{2} \quad \mathrm{~L} \cdot \mathrm{min}^{-1}$ & $1.2 \pm 0.5$ & $1.2 \pm 0.6$ & $1.0 \pm 0.3$ & $1.0 \pm 0.3$ \\
\hline$V^{\prime} \mathrm{CO}_{2} \mathrm{~L} \cdot \mathrm{min}^{-1}$ & $1.2 \pm 0.5$ & $1.2 \pm 0.6$ & $1.0 \pm 0.4$ & $1.0 \pm 0.4$ \\
\hline$P{\mathrm{a}, \mathrm{O}_{2}} \mathrm{kPa}$ & $7.3 \pm 0.7$ & $6.9 \pm 0.7$ & $7.2 \pm 1.0$ & $6.7 \pm 1.0^{* *}$ \\
\hline $\mathrm{Pa}_{\mathrm{a}, \mathrm{CO}_{2}} \quad \mathrm{kPa}$ & $5.7 \pm 1.1$ & $5.7 \pm 0.8$ & $5.9 \pm 1.2$ & $5.8 \pm 1.3$ \\
\hline $\begin{array}{c}\Delta \text { base excess } \\
\mathrm{mmol} \cdot \mathrm{L}^{-1}\end{array}$ & $-5.3 \pm 2.8$ & $-5.7 \pm 2.8$ & $-4.8 \pm 3.3$ & $-5.4 \pm 3.4$ \\
\hline$P(\mathrm{~A}-\mathrm{a}), \mathrm{O}_{2} \quad \mathrm{kPa}$ & $7.7 \pm 1.3$ & $8.2 \pm 1.5$ & $7.4 \pm 1.3$ & $8.1 \pm 1.5$ \\
\hline $\begin{array}{l}\text { Dyspnoea } \\
\text { Borg scale }\end{array}$ & $7.3 \pm 2.4$ & $5.8 \pm 1.9$ & $6.6 \pm 2.1$ & $5.3 \pm 1.2$ \\
\hline
\end{tabular}

Values are presented as mean \pm SD. $W$ max: maximum workload; $f_{\mathrm{C}}$ : cardiac frequency; $V^{\prime} \mathrm{E}$ : minute ventilation; $V^{\prime} \mathrm{O}_{2}$ : oxygen consumption; $V^{\prime} \mathrm{CO}_{2}$ : carbon dioxide production; $\Delta$ base excess: base excess after-before the test. For further definitions see legend to table $1 . * *: \mathrm{p}<0.01$, within-group comparison before versus after rehabilitation. 
Table 3. - Single-stage exercise test and activities of daily life breathing room air before and after pulmonary rehabilitation

\begin{tabular}{|c|c|c|c|c|}
\hline & \multicolumn{2}{|c|}{ GET/RA } & \multicolumn{2}{|c|}{$\mathrm{GET} / \mathrm{O}_{2}$} \\
\hline & Before & After & Before & After \\
\hline \multicolumn{5}{|c|}{ Single-stage cycle exercise test } \\
\hline $\begin{array}{l}\text { Cycling time } \\
\text { min }\end{array}$ & $6.5 \pm 4.4$ & $6.5 \pm 4.4$ & $4.5 \pm 2.5$ & $6.7 \pm 3.7$ \\
\hline$f \mathrm{C}$ beats $\cdot \mathrm{min}^{-1}$ & $124 \pm 22$ & $125 \pm 19$ & $116 \pm 21$ & $126 \pm 21$ \\
\hline$V^{\prime} \mathrm{E} \quad \mathrm{L} \cdot \mathrm{min}^{-1}$ & $39 \pm 15$ & $40 \pm 21$ & $32 \pm 14$ & $36 \pm 15$ \\
\hline$V^{\prime} \mathrm{CO}_{2} \mathrm{~L} \cdot \mathrm{min}^{-1}$ & $1.0 \pm 0.4$ & $1.1 \pm 0.5$ & $0.8 \pm 0.3$ & $1.0 \pm 0.4$ \\
\hline $\mathrm{Sa}_{\mathrm{a}, \mathrm{O}_{2}} \%$ & $86 \pm 4$ & $83 \pm 6$ & $86 \pm 4$ & $83 \pm 6$ \\
\hline $\begin{array}{l}\text { Dyspnoea } \\
\text { Borg scale }\end{array}$ & $5.8 \pm 0.9$ & $6.2 \pm 1.7$ & $6.1 \pm 1.8$ & $5.8 \pm 1.7$ \\
\hline 6MWD m & $487 \pm 191$ & $610 \pm 166^{* *}$ & $389 \pm 140$ & $475 \pm 180 * *$ \\
\hline$f_{\mathrm{C}}$ beats $\cdot \mathrm{min}^{-1}$ & $118 \pm 10$ & $126 \pm 11$ & $110 \pm 23$ & $124 \pm 19 * *$ \\
\hline $\mathrm{Sa}_{\mathrm{a}, \mathrm{O}_{2}} \%$ & $84 \pm 5$ & $82 \pm 5$ & $85 \pm 6$ & $83 \pm 6$ \\
\hline $\begin{array}{l}\text { Dyspnoea } \\
\text { Borg scale }\end{array}$ & $4.8 \pm 1.2$ & $5.1 \pm 1.6$ & $4.5 \pm 1.1$ & $4.8 \pm 1.6$ \\
\hline Stair-climbing & n $29 \pm 12$ & $41 \pm 18 * *$ & $22 \pm 10$ & $30 \pm 14 * *$ \\
\hline Weight-lifting & n $36 \pm 14$ & $52 \pm 18 * *$ & $37 \pm 9$ & $46 \pm 7 * *$ \\
\hline
\end{tabular}

Values are presented as mean \pm SD. For exercise testing protocols for stair-climbing and weight-lifting see text. $\mathrm{Sa}, \mathrm{O}_{2}$ : oxygen saturation (pulse oximeter); 6MWD: 6 min walking distance. For further definitions see legends to tables 1 and 2 . **: $\mathrm{p}<0.01$, within-group comparison before versus after rehabilitation.

The performance during stair-climbing and weightlifting increased significantly by $20-40 \%$ in both groups (table 3).

No significant differences were observed in exercise performance, responses to exercise and effects of training between the two groups.

\section{Oxygen-supplemented exercise testing}

Supplemental oxygen had acute effects on exercise performance before and after training. The effects did not differ between the two training groups. Before training, oxygen improved $W \max$ during maximal incremental cycle exercise in the GET/RA group by 12 (19) $\mathrm{W}(\mathrm{p}=0.04)$, and in the $\mathrm{GET} / \mathrm{O}_{2}$ group by 4 (19)
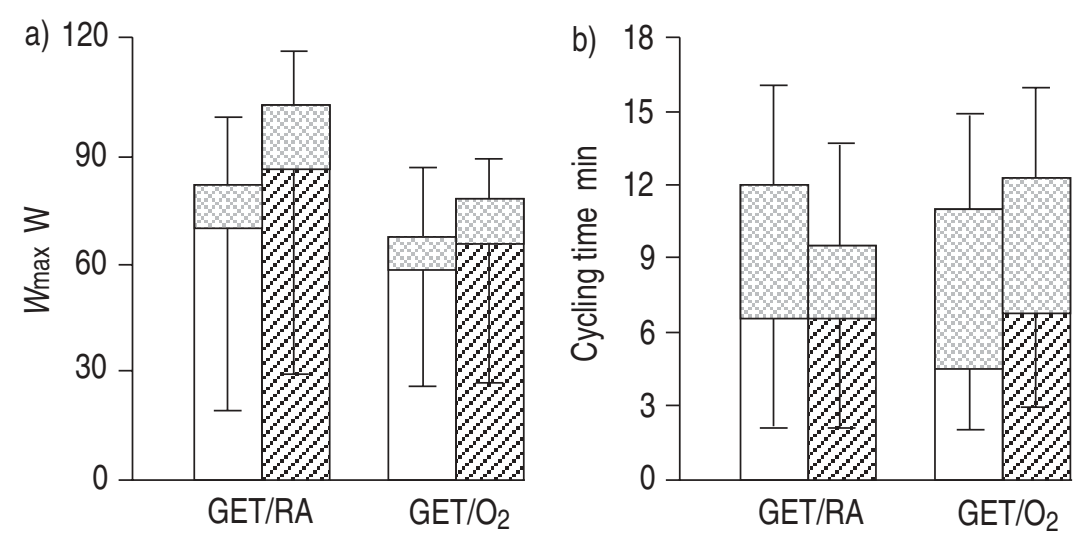

Table 4. - Oxygen supplemented exercise testing before and after pulmonary rehabilitation

\begin{tabular}{|c|c|c|c|c|}
\hline & \multicolumn{2}{|c|}{ GET/RA } & \multicolumn{2}{|c|}{$\mathrm{GET} / \mathrm{O}_{2}$} \\
\hline & Before & After & Before & After \\
\hline \multicolumn{5}{|c|}{ Maximal incremental cycle exercise test } \\
\hline$W \max \mathrm{W}$ & $82 \pm 53$ & $104 \pm 68^{+\#}$ & $62 \pm 27$ & $79 \pm 40^{+\#}$ \\
\hline$f_{\mathrm{C}}$ beats $\cdot \mathrm{min}^{-1}$ & $132 \pm 21$ & $139 \pm 30$ & $123 \pm 19$ & $129 \pm 21$ \\
\hline$V^{\prime} \mathrm{E} \quad \mathrm{L} \cdot \mathrm{min}^{-1}$ & $41 \pm 20$ & $45 \pm 23$ & $35 \pm 14$ & $39 \pm 17$ \\
\hline$V^{\prime} \mathrm{CO}_{2} \mathrm{~L} \cdot \mathrm{min}^{-1}$ & $1.2 \pm 0.6$ & $1.4 \pm 0.7^{+\#}$ & $1.0 \pm 0.4$ & $1.2 \pm 0.5^{+\#}$ \\
\hline${\mathrm{Sa}, \mathrm{O}_{2}}_{2} \%$ & $94 \pm 3$ & $94 \pm 4$ & $93 \pm 5$ & $93 \pm 6$ \\
\hline $\begin{array}{l}\text { Dyspnoea } \\
\text { Borg scale }\end{array}$ & $5.8 \pm 1.5$ & $6.3 \pm 1.4$ & $6.4 \pm 2.3$ & $5.8 \pm 1.9$ \\
\hline \multicolumn{5}{|c|}{ Single-stage cycle exercise test } \\
\hline$\underset{\text { min }}{\text { Cycling time }}$ & $11.4 \pm 4.7^{\#}$ & $9.4 \pm 5.2^{\#}$ & $11.0 \pm 4.5^{\#}$ & $12.2 \pm 4.4^{\#}$ \\
\hline$f \mathrm{C}$ beats $\cdot \mathrm{min}^{-1}$ & $129 \pm 18$ & $125 \pm 20$ & $121 \pm 18$ & $127 \pm 25$ \\
\hline$V^{\prime} \mathrm{E} \quad \mathrm{L} \cdot \mathrm{min}^{-1}$ & $38 \pm 15$ & $39 \pm 21$ & $34 \pm 15$ & $36 \pm 14$ \\
\hline$V^{\prime} \mathrm{CO}_{2} \quad \mathrm{~L} \cdot \mathrm{min}^{-1}$ & $1.1 \pm 0.4$ & $1.1 \pm 0.5$ & $0.9 \pm 0.3$ & $1.0 \pm 0.3$ \\
\hline $\mathrm{Sa}_{\mathrm{a}, \mathrm{O}_{2}} \%$ & $95 \pm 2$ & $95 \pm 2$ & $95 \pm 2$ & $95 \pm 2$ \\
\hline $\begin{array}{l}\text { Dyspnoea } \\
\text { Borg scale }\end{array}$ & $6.0 \pm 1.5$ & $5.7 \pm 2.2$ & $6.3 \pm 2.1$ & $5.0 \pm 1.5$ \\
\hline 6MWD m & $529 \pm 193^{\#}$ & $637 \pm 221^{+}$ & $436 \pm 162^{\#}$ & $504 \pm 164^{+}$ \\
\hline$f_{\mathrm{C}}$ beats $\cdot \mathrm{min}^{-1}$ & $121 \pm 11$ & $125 \pm 15$ & $111 \pm 24$ & $121 \pm 22^{+}$ \\
\hline $\mathrm{Sa}_{\mathrm{a}, \mathrm{O}_{2}} \%$ & $90 \pm 5$ & $87 \pm 8$ & $92 \pm 3$ & $91 \pm 3$ \\
\hline $\begin{array}{l}\text { Dyspnoea } \\
\text { Borg scale }\end{array}$ & $4.8 \pm 1.5$ & $4.7 \pm 1.5$ & $4.8 \pm 2.6$ & $4.3 \pm 1.4$ \\
\hline
\end{tabular}

Values are presented as mean \pm SD. For definitions see legends to tables $1-3 .^{+}: \mathrm{p}<0.01$, within-group comparison before versus after rehabilitation; $\#$ : $\mathrm{p}<0.01$, oxygen-supplemented exercise test versus exercise test on room air.

$\mathrm{W}(\mathrm{p}=0.15)$. After training, oxygen significantly increased $W$ max in both groups by 17 (15) and 13 (11) W, respectively (fig. 1a).

Supplemental oxygen significantly increased cycling time during single-stage exercise before training by 4.8 (4.8) in the GET/RA group and by 6.5 (3.9) $\mathrm{min}$ in the GET $/ \mathrm{O}_{2}$ group, and after training by 2.9 (4.3) and 5.5 (3.9) min, respectively (fig. 1b).

Before training, supplemental oxygen significantly increased $6 \mathrm{MWD}$ by 42 (30) in the GET/RA group and by $47(63) \mathrm{m}$ in the GET/O $\mathrm{O}_{2}$ group (fig. 1c). The acute effect of oxygen on 6MWD was lost after training.

Fig. 1. - Exercise performance on room air before $(\square)$ and after ( $\square$ ) general exercise training while breathing room air (GET/RA; n=12) and supplemental oxygen $\left(\mathrm{GET} / \mathrm{O}_{2} ; \mathrm{n}=12\right)$. The acute effects of supplemental oxygen are depicted in the closed bars $(\square)$. Error bars indicate standard deviation. a) Training significantly increased maximal workload $\left(W_{\max }\right)$ on room air in the GET/RA group (p<0.01), but not in the GET/O $\mathrm{O}_{2}$ group. Supplemental oxygen increased $W \max$ before and after training in both groups, but these improvements were significant only after training $(\mathrm{p}<0.01)$. b) Training did not improve cycling time during single-stage exercise on room air at a constant workload of $65 \%$ of $W$ max in both groups. Supplemental oxygen significantly increased cycling time both before and after training in both groups (p<0.01). c) Training significantly increased 6 min walking distance $(6 \mathrm{MWD})$ on room air in both groups $(\mathrm{p}<0.01)$. Supplemental oxygen significantly increased $6 \mathrm{MWD}$ before training in both groups $(\mathrm{p}<0.01)$. After training, no further improvement in $6 \mathrm{MWD}$ was observed. Differences between groups were not significant. 
Table 5. - Quality of life (CRDQ) before and after pulmonary rehabilitation

\begin{tabular}{lcccc}
\hline & \multicolumn{2}{c}{ GET/RA } & \multicolumn{2}{c}{ GET/O } \\
& Before & After & Before & After \\
\hline Dyspnoea & $14.9 \pm 5.8$ & $21.6 \pm 4.5^{* *}$ & $15.9 \pm 5.3$ & $21.6 \pm 5.5^{* *}$ \\
Fatigue & $17.4 \pm 4.8$ & $20.0 \pm 4.5$ & $15.5 \pm 4.3$ & $18.8 \pm 3.9$ \\
Emotional & $32.0 \pm 6.9$ & $35.2 \pm 8.5$ & $29.5 \pm 7.1$ & $35.3 \pm 6.3^{* *}$ \\
$\quad$ function & & & & \\
Mastery & $20.4 \pm 4.1$ & $22.8 \pm 3.7^{* *}$ & $18.0 \pm 5.5$ & $22.1 \pm 3.3^{* *}$ \\
Total score & $85 \pm 16$ & $100 \pm 17^{* *}$ & $79 \pm 18$ & $98 \pm 16^{* *}$ \\
\hline
\end{tabular}

Values are presented as mean \pm SD. CRDQ: Chronic Respiratory Disease Questionnaire. **: $\mathrm{p}<0.01$, within-group comparison before versus after rehabilitation.

The acute effects of oxygen on $W \max$, cycling time and $6 \mathrm{MWD}$ before training did not differ significantly from those after training.

Training significantly increased $W \max$, peak $V^{\prime} \mathrm{CO}_{2}$ and 6MWD while breathing oxygen, to a similar extent in both groups (table 4). The increase in 6MWD was achieved at a higher $f \mathrm{C}$ in the GET/O $\mathrm{O}_{2}$ group, while the $f \mathrm{C}$ did not change in the GET/RA group. Differences between groups were not significant.

\section{Quality of life}

Before rehabilitation, CRDQ scores were similar in both groups. Rehabilitation significantly increased total CRDQ score by 15 (7) points in the GET/RA group and by 19 (14) points in the GET/ $\mathrm{O}_{2}$ group. The improvements were equally distributed among the four dimensions, but were not significant for the dimension "fatigue" in both groups and for "emotional function" in the GET/RA group (table 5).

\section{Discussion}

In this study, we investigated whether patients with severe COPD and hypoxaemia at peak exercise might benefit from supplemental oxygen during training. Exercise training, both on air and oxygen, improved exercise performance and quality of life. Although supplemental oxygen had acute beneficial effects on exercise performance, oxygen-supplemented exercise training did not add to the effects of training while breathing room air.

The diffusion capacity below $50 \%$ of predicted [30], the elevated $P(\mathrm{~A}-\mathrm{a}) \mathrm{O}_{2}$ at rest and the increase in $P(\mathrm{~A}-\mathrm{a}) \mathrm{O}_{2}$ by more than $3 \mathrm{kPa}$ during exercise [31] indicate that a diffusion-perfusion limitation, rather than hypoventilation, was the cause of the hypoxaemia at peak exercise in these patients $[1,32]$.

\section{Pulmonary rehabilitation in patients with severe COPD}

Several studies have reported beneficial effects of pulmonary rehabilitation in patients with moderateto-severe COPD, some of whom were hypoxaemic at rest or during exercise [13-15, 33, 34]. These studies showed improvements in maximal workload [14, 15], endurance exercise capacity [13-15, 34], walking distance [13], perceived breathlessness [14, 15], and quality of life [13]. A physiological training effect in terms of an increase in peak $V^{\prime} \mathrm{O}_{2}$, and reduction in $f \mathrm{C}$, blood lactate levels and ventilation at identical work rates after training, has been reported in some studies [14, 15, 34], but was not found by others $[13,33]$. The effects in patients who developed hypoxaemia during the training were not described separately.

The patients in the present study were normoxic at rest and hypoxaemic at peak exercise. During the training they desaturated, but $\mathrm{Sa}_{\mathrm{a}} \mathrm{O}_{2}$ was not allowed to fall below $90 \%$. Training did not increase aerobic capacity while breathing room air. The improvement in exercise performance was achieved in part by an improvement in exercise efficiency $\left(\mathrm{W} / V^{\prime} \mathrm{O}_{2}\right)$. Since the Borg score at peak exercise tended to decrease after training, both desensitization to dyspnoea and motivation may have played a role in patients in whom training proportionally improved $W \max$ and peak $V^{\prime} \mathrm{O}_{2}$.

\section{Acute effects of supplemental oxygen on exercise per- formance}

In patients with COPD, the acute administration of supplemental oxygen has been shown to improve exercise performance [3-6]. Breathing supplemental oxygen increased $W \max$ during cycle exercise by $10 \%$ [6], endurance cycling and walking time by 88 and $59 \%$, respectively, and 6MWD by $17 \%$ [5] in comparison with room air. We found similar results in the present patients. Since the ventilatory equivalent for $V^{\prime} \mathrm{O}_{2}$ is higher for walking than for cycling, and 6MWD is a submaximal exercise test, diffusion-perfusion may be less important as a factor limiting 6MWD. Hence, the acute effect of supplemental oxygen on 6MWD was small as compared to performance during cycling at high exercise intensities. After training, this difference became even more clear, as breathing oxygen did not improve 6MWD further in comparison with room air. This was caused, in part, by the effect of training on 6MWD, which far exceeded the acute effect of oxygen.

\section{Effects of oxygen-supplemented exercise training}

Few studies have investigated the effects of training with supplemental oxygen in patients with COPD. In the study by Zack and Palange [17], oxygen-supplemented training significantly increased $W_{\max }$ while breathing oxygen, whereas $W \max$ and peak $V^{\prime} \mathrm{O}_{2}$ on room air did not improve. Endurance cycling time and $12 \mathrm{~min}$ walking distance significantly improved both on air and oxygen [17]. DEGRE et al. [16] reported an increase in peak $V^{\prime} \mathrm{O}_{2}$ by $10 \%$ after training with supplemental oxygen (3-4 L'min ${ }^{-1}$, which was related to the oxygen tension during exercise [16]. Maximal cardiac output and stroke volume did not change [16]. In these studies, however, no comparison was made with a control group breathing room air.

In the present study, training with supplemental oxygen did not add to the effects of training on room air. Recently, similar results have been reported in patients who did not desaturate during exercise [35]. Comparing exercise tests on oxygen, however, our study showed that training improved $W$ max and peak $V^{\prime} \mathrm{CO}_{2},\left(V^{\prime} \mathrm{O}_{2}\right.$ could not be measured under these conditions) in both groups. 
This implies a physiological training effect, regardless of the use of oxygen during the training. These training effects were not observed during exercise testing on room air, possibly because hypoxaemia limited exercise performance.

In contrast to previous studies, training with or without supplemental oxygen did not improve endurance cycling time on air and oxygen in the present patients [13-15, 17, 34]. Furthermore, endurance work (constant workload $\times$ endurance cycling time) did not improve in either group. Study population and test design may explain the results in our study. Hypoxaemia and the high constant workload, which was adjusted to the actual $W \max$ after training, may have contributed to the poor performance during the single-stage exercise test on room air. Indeed, endurance cycling time increased considerably when oxygen was administered. However, the single-stage test was limited to $15 \mathrm{~min}$, which may have concealed some of the effects of training.

Many factors may account for the absence of an additional effect of training with supplemental oxygen, as observed in the present study. Firstly, the contribution of hypoxaemia to the exercise limitation is still uncertain, and the mechanisms by which oxygen affects exercise performance are complex [6-11]. The present study confirmed previous reports showing that the acute effects of oxygen, as well as the effects of training, correlated poorly with lung function parameters or blood gas values at rest or during exercise [5, 6, 17]. Furthermore, in the present study, the acute effects of oxygen did not predict the effects of training in individual subjects. Hence, patients with a poor response to oxygen are not necessarily poor candidates for training. These findings suggest that oxygen and training may influence exercise performance by different mechanisms.

Secondly, in spite of the acute effects of oxygen, the $\mathrm{GET} / \mathrm{O}_{2}$ group did not achieve higher work rates during cycle exercise training than the GET/RA group. Thus, the total amount of work performed during the training was equal in both groups. This was due to the training regimen, which consisted of interval training with bouts of exercise of $3 \mathrm{~min}$ or less. Endurance exercise was not performed during the training. Thus, the GET/RA group could keep $\mathrm{Sa}_{2} \mathrm{O}_{2}$ above $90 \%$ at relatively high work rates. As a result, during exercise training, the patients in both groups were similarly limited by their ventilatory impairment and by breathlessness rather than by hypoxaemia.

Thirdly, increased blood lactate levels during exercise have been shown to enhance the effects of training in patients with COPD [34]. In healthy subjects and in patients with peripheral vascular disease, muscle ischaemia is a potent stimulus for improving endurance exercise [36]. Since supplemental oxygen abolishes the desaturation and reduces lactate levels during exercise $[4,37]$, it might also have reduced the training stimulus in these patients.

Finally, in addition to the diffusion-perfusion limitation in the lungs, a diffusion limitation at the level of the skeletal muscles may be present $[38,39]$. In healthy subjects under hypoxaemic conditions, muscle diffusion capacity was an important factor limiting maximal $V^{\prime} \mathrm{O}_{2}$, especially in deconditioned muscles [39]. Supplemental oxygen may, thus, fail to enhance muscle oxygen utilization during the training in patients with COPD in whom peripheral muscle weakness may exist [40].

\section{Clinical implications and conclusions}

Supplemental oxygen attenuates the increase in $P$ pa during exercise in patients with COPD [41]. However, it is not known whether this may prevent the development of pulmonary hypertension. In the present study, training did not change resting $\bar{P}$ pa. Thus, training both on air and oxygen may be safe, as long as $\mathrm{Sa}_{\mathrm{a}} \mathrm{O}_{2}$ is kept above $90 \%$ during exercise.

This study shows that pulmonary rehabilitation improves functional capacity and quality of life in patients with severe chronic obstructive pulmonary disease and hypoxaemia at peak exercise. The increase in quality of life scores after pulmonary rehabilitation is considered clinically relevant [42], and is in agreement with previous studies [43]. Breathing supplemental oxygen during the training had no advantage over training while breathing room air.

Acknowledgements: The authors wish to thank Th.M. de Boo and W.J.G.M. Lemmens of the Medical Statistical Department for their statistical advice.

\section{References}

1. Rodriguez-Roisin R, Wagner PD. Clinical relevance of ventilation-perfusion inequality determined by inert gas elimination. Eur Respir J 1990; 3: 469-482.

2. Matthay RA, Wiedemann HP. Cardiovascular pulmonary interaction in chronic obstructive pulmonary disease with special reference to the pathogenesis and management of cor pulmonale. Med Clin North Am 1990; 74: 571-618.

3. Bradley BL, Garner AE, Billiu D, Mestas JM, Forman J. Oxygen-assisted exercise in chronic obstructive lung disease. Am Rev Respir Dis 1978; 118: 239-243.

4. Stein DA, Bradley BL, Miller WC. Mechanisms of oxygen effects on exercise in patients with chronic obstructive pulmonary disease. Chest 1982; 81: 6-10.

5. Davidson AC, Leach R, George RJD, Geddes DM. Supplemental oxygen and exercise ability in chronic obstructive airways disease. Thorax 1988; 43: 965-971.

6. Light RW, Mahutte CK, Stansbury CW, Fischer CE, Brown SE. Relationship between improvement in exercise performance with supplemental oxygen and hypoxic ventilatory drive in patients with chronic airflow obstruction. Chest 1989; 95: 751-756.

7. Criner GJ, Celli BR. Ventilatory muscle recruitment in exercise with $\mathrm{O}_{2}$ in obstructed patients with mild hypoxemia. J Appl Physiol 1987; 63: 195-200.

8. Bye PTP, Esau SA7 Walley KR, Macklem PT, Pardy RL. Ventilatory muscles during exercise in air and oxygen in normal man. J Appl Physiol: Respirat Environ Exercise Physiol 1984; 56: 464-471.

9. Jardim J, Farkas G, Prefaut C, Thomas D, Macklem PT, Roussos Ch. The failing inspiratory muscles under normoxic and hypoxic conditions. Am Rev Respir Dis 1981; 124: 274-279.

10. Wuyam B, Payen JF, Levy P, et al. Metabolism and aerobic capacity of skeletal muscle in chronic respiratory failure related to chronic obstructive pulmonary disease. Eur Respir J 1992; 5: 157-162. 
11. Woodcock AA, Gross ER, Geddes DM. Oxygen relieves breathlessness in "pink puffers". Lancet 1981; i: 907-909.

12. Donner CF, Howard P. Pulmonary rehabilitation in chronic obstructive pulmonary disease (COPD) with recommendations for its use. Eur Respir J 1992; 5: 266-275.

13. Niederman MS, Clemente PH, Fein AM, et al. Benefits of a multidisciplinary pulmonary rehabilitation program. Chest 1991; 99: 798-804.

14. Punzal PA, Ries AL, Kaplan RM, Prewitt LM. Maximum intensity exercise training in patients with chronic obstructive pulmonary disease. Chest 1991; 100: 618-623.

15. Ries AL, Kaplan RM, Limberg TM, Prewitt LM. Effects of pulmonary rehabilitation on physiologic and psychosocial outcomes in patients with chronic obstructive pulmonary disease. Ann Intern Med 1995; 122: 823-832.

16. Degre S, Sergysels R, Messin R, et al. Hemodynamic responses to physical training in patients with chronic lung disease. Am Rev Respir Dis 1974; 110: 395-402.

17. Zack MB, Palange AV. Oxygen supplemented exercise of ventilatory and nonventilatory muscles in pulmonary rehabilitation. Chest 1985; 88: 669-675.

18. American Thoracic Society. Standards for the diagnosis and care of patients with chronic obstructive pulmonary disease. Am J Respir Crit Care Med 1995; 152: S77-S120.

19. Kitabatake A, Inoue M, Asao M, et al. Noninvasive evaluation of pulmonary hypertension by a pulsed Doppler technique. Circulation 1983; 68: 302-309.

20. Casaburi R. Exercise training in chronic obstructive lung disease. In: Casaburi R, Petty TL, eds. Principles and Practice of Pulmonary Rehabilitation, Philadelphia, W.B. Saunders Co., 1993: pp. 204-224.

21. Rooyackers J, Fluit M, Dekhuijzen P, Herwaarden van $\mathrm{C}$, Folgering $\mathrm{H}$. The intensity of a training programme for COPD patients. Eur Respir J 1993; 6 (Suppl. 17): 256s.

22. Quanjer PhH. Standardized lung function testing. Eur Respir J 1993; 6 (Suppl. 16): 3-120s.

23. Folgering HThM, Doorn van P, Cox NJM. A prediction equation for $W_{\max }$ in COPD patients. Eur Respir J 1988; 1, Suppl. 1: 67s.

24. Borg GAV. Psychophysical bases of perceived exertion. Med Sci Sports Exer 1982; 14: 377-381.

25. Carter R, Peavler M, Zinkgraf S, Williams J, Fields S. Predicting maximal exercise ventilation in patients with chronic obstructive pulmonary disease. Chest 1987; 92: 253-259.

26. Butland RJA, Pang J, Gross ER, Woodcock A, Geddes DM. Two-, six- and twelve-minute walking tests in respiratory disease. $\mathrm{Br}$ Med $J$ 1982; 284: 1607-1608.

27. Guyatt GH, Pugsley SO, Sullivan MJ, et al. Effect of encouragement on walking test performance. Thorax 1984; 39: 818-822.

28. Rooyackers J, Dekhuijzen P, van Herwaarden C, Folgering H. Upper limb activities in COPD patients: the reproducibility of a weight-lift test. Eur Respir J 1992; 5 (Suppl. 15): 218s.
29. Guyatt GH, Berman LB, Townsend M, Pugsley SO, Chambers LW. A measure of quality of life for clinical trials in chronic lung disease. Thorax 1987; 42: 773-778.

30. Sue DY, Oren A, Hansen JE, Wasserman K. Diffusing capacity for carbon monoxide as a predictor of gas exchange during exercise. $N$ Engl J Med 1987; 316: 1301-1306.

31. Whipp BJ, Wasserman K. Alveolar-arterial gas tensions differences during graded exercise. J Appl Physiol 1969; 27: 361-365.

32. Wasserman K, Hansen JE, Sue DY, Whipp BJ. Measurement of the physiological response to exercise. In: Principles of Exercise Testing and Interpretation. 1st Edn. Philadelphia, Lea \& Febiger, 1987; pp. 27-46.

33. Chester EH, Belman MJ, Bahler RC, Baum GL, Schey G, Buch P. Multidisciplinary treatment of chronic pulmonary insufficiency. 3. The effect of physical training on cardiopulmonary performance in patients with chronic obstructive pulmonary disease. Chest 1977; 72 : 695-702.

34. Casaburi R, Patessio A, Ioli F, Zanaboni S, Donner CF, Wasserman K. Reductions in exercise lactic acidosis and ventilation as a result of exercise training in patients with obstructive lung disease. Am Rev Respir Dis 1991; 143: 9-18.

35. Patessio A, Casaburi R, Carone M, et al. Effects of supplemental oxygen $v s$ room air breathing during training on exercise responses in nondesaturating COPD patients. Eur Respir J 1996; 9, Suppl. 23: 379s.

36. Sundberg CJ, Eiken O, Nygren A, Kaijser L. Effect of one-legged ischemic training on dynamic muscle performance and peak oxygen uptake in man. Acta Physiol Scand 1993; 148: 13-19.

37. Adams RP, Welch HG. Oxygen uptake, acid-base status, and performance with varied inspired oxygen fractions. J Appl Physiol: Respirat Environ Exercise Physiol 1980; 49: 863-868.

38. Koike A, Wasserman K, McKenzie DK, Zanconato S, Weiler-Ravell D. Evidence that diffusion limitation determines oxygen uptake kinetics during exercise in humans. J Clin Invest 1990; 86: 1698-1706.

39. Wagner PD. Algebraic analysis of the determinants of $V^{\prime} \mathrm{O}_{2}$ max. Respir Physiol 1993; 93: 221-237.

40. Gosselink R, Troosters T, Decramer M. Peripheral muscle weakness contributes to exercise limitation in COPD. Am J Respir Crit Care Med 1996; 153: 976-980.

41. Burrows B, Kettel LJ, Niden AH. Patterns of cardiovascular dysfunction in chronic obstructive lung disease. N Engl J Med 1972; 286: 912-918.

42. Jaeschke R, Singer J, Guyatt GH. Measurement of health status: ascertaining the minimum clinically important difference. Control Clin Trials 1989; 10: 407-415.

43. Wijkstra PJ, Van Altena R, Kraan J, Otten V, Postma DS, Koeter GH. Quality of life in patients with chronic obstructive pulmonary disease improves after rehabilitation at home. Eur Respir J 1994; 7: 269-273. 